\title{
Avaliação financeira dos mecanismos de concessão com prazo variável
}

\author{
Homero Neves da Silva, Fernando Dutra Michel e Luiz Afonso dos Santos Senna \\ LASTRAN - Universidade Federal do Rio Grande do Sul, Brasil
}

\author{
Antonio Núñez \\ Laboratoire d'Economie des Transports - Université de Lyon, França
}

RESUMO: Este trabalho é devotado à avaliação do risco de tráfego em concessões de infra-estruturas rodoviárias. Dentre os principais meios encontrados para minimizar os efeitos do risco de tráfego aos concessionários encontrase a utilização de mecanismos de concessão baseado em contratos com prazo variável. Dois mecanismos têm sido desenvolvidos com este objetivo e foram avaliados neste trabalho: LPVR, proposto por Engel, Fischer e Galetovic e implantado no Chile em meados da década de 1990; e LPVNR, proposto por Nombela e de Rus a partir do final da mesma década. A avaliação dos mecanismos foi realizada utilizando simulação Monte Carlo. Para a realização da avaliação, foi desenvolvido um modelo financeiro que propiciasse análises de projetos com duração não definida exante. As variáveis utilizadas nos testes foram: as taxas de desconto utilizadas nos projetos; os horizontes de tempo das concessões (duração esperada); e a extensão máxima que a duração pode ter, além da duração esperada.

ABSTRACT: This work is devoted to assess the traffic risk in road infrastructure concessions. One of the many ways to minimize the consequences of the traffic risks faced by concessionaires is to use an auction mechanism based on flexible-term contracts. Two mechanisms have been built on with this aim and are assessed in this work: LPVR, proposed by Engel, Fischer and Galetovic and put in practice in Chile in the middle of the 1990'; and LPVNR, proposed by Nombela and de Rus in the latest years of the same decade. The assessment of the mechanisms has been performed using Monte Carlo simulation technique. To perform the analysis, a financial model that makes possible analysis of projects with uncertain term has been built. The variables used in the tests were: projects discount rates; expected duration of the concession; and the maximum extension of the concession duration over the expected duration.

\section{INTRODUÇÃO}

Entre os principais problemas encontrados em concessões de infra-estruturas rodoviárias estão os riscos associados aos projetos e a sua alocação entre as partes envolvidas nas parcerias entre os setores público e privado. As incertezas associadas ao tráfego são, possivelmente, a principal fonte de risco para projetos de concessão de infra-estruturas rodoviárias (Fishbein e Babbar, 1996). Para solucionar os problemas trazidos pelo risco de tráfego, uma das soluções é o oferecimento de garantias. Entretanto, estas garantias têm outras conseqüências sobre as concessões que podem ser tão problemáticas quanto o próprio risco de tráfego.

A partir de meados da década de 1990, pesquisadores iniciaram o desenvolvimento de mecanismos de concessão que possibilitassem a redução dos riscos de tráfego. Estes mecanismos transferem o risco do concessionário para os usuários, na forma de variações no prazo de duração das concessões. A utilização de mecanismos de prazo variável em concessões rodoviária foi iniciada no Reino Uni- do. Entretanto, pesquisas mais aprofundadas nessa área foram realizadas no Chile, com Engel, Fischer e Galetovic, a partir de 1995, que desenvolveram o mecanismo LPVR, e na Espanha, com Nombela e de Rus, a partir de 1999, com o desenvolvimento do mecanismo LPVNR.

O Brasil apresenta um dos maiores programas de concessões de infra-estruturas rodoviárias do mundo (Machado, 2002), tendo sido posto em prática durante a década de 1990 pelo Governo Federal, governos estaduais e municipais. Este programa foi estruturado para ter sido dado continuidade, especialmente na esfera federal, onde estavam previstos mais dois grupos de rodovias passíveis de concessão (DNER, 2000). Uma das características marcantes deste programa é a elevada TIR dos projetos e grandes prazos de concessão, que variam entre $15 \mathrm{e}$ 30 anos, em sua maioria.

As novas concessões previstas foram adiadas, não tendo sido licitadas até o momento. Entretanto, as discussões a respeito desse assunto não foram esquecidas, tendo sido divulgada a intenção do Gover- 
no Federal de dar continuidade aos projetos previstos. Junto com o a realização de novas concessões, tem sido demonstrado o interesse na introdução de aperfeiçoamentos na modelagem de novas etapas do programa federal de concessões. Dentre as novidades discutidas inclui-se a utilização de mecanismos de prazo variável. (Ministério dos Transportes, 2004)

Poucos são os exemplos de estudos realizados no Brasil com o objetivo de discutir a utilização destes mecanismos no país. Dentre os exemplos, pode-se destacar o texto produzido por Pires e Giambiagi, no ano 2000. Entretanto, o texto limita-se ao mecanismo desenvolvido por Engel, Fischer e Galetovic, além de não aprofundar o debate sobre a aplicação deste mecanismo no cenário brasileiro, limitando-se mais às questões legais do país.

Além da falta de estudos no Brasil, mesmo fora do país, as avaliações dos mecanismo de prazo variável têm como foco a visão do poder concedente, sem buscar identificar como concessões deste tipo afetam os concessionários. Também, poucos são os estudos que avaliam como o ambiente imposto às concessões influencia os resultados de concessões com estes mecanismos, como os prazos de concessão, alto custo do capital etc.

Considerando o desenvolvimento do mecanismo de Nombela e de Rus $(2001,2004)$, além do debate sobre a utilização destes mecanismos em concessões de infra-estruturas no Brasil, este trabalho consiste em avaliar o impacto que algumas variáveis chave apresentam sobre os resultados das concessões sujeitas a duração variável.

\section{GARANTIAS E MECANISMOS DE CONCESSÃO COM PRAZO VARIÁVEL}

As concessões de rodovias no Brasil, assim como ocorrido em muitos países do mundo, foram licitadas conforme o conceito de competição pelo mercado difundido por Demsetz (1968), com prazo de concessão fixo. Embora sejam amplamente utilizadas, as concessões de rodovias com prazo fixo apresentam problemas. Baseado nas idéias de Engel, Fischer e Galetovic (1996, 1997a, 1997b, 1997c), Tirole (1997) e Nombela e De Rus (2004), podemos agrupar os pontos negativos de concessões com prazo fixo em:

- maior exposição a renegociações oportunísticas;

- grande possibilidade de seleção de concessionários que não sejam os mais eficientes;

- possibilidade de desperdícios econômicos com a produção de diversos estudos de tráfego;

- dificuldade de executar modificações nos contratos;
- incertezas associadas às previsões de tráfego.

Desses pontos negativos, o risco de tráfego tem gerado grande debate. A solução tradicional para enfrentar os problemas causados pelo risco de tráfego em um programa de concessão rodoviária é oferecer garantias para os débitos, receita ou tráfego, como amplamente utilizado no Chile (Gómez-Lobo e Hinojosa, 2000). Para Tirole (1997), o oferecimento de garantias facilita muito o endividamento das empresas concessionárias, fato esse que levou à introdução de garantias de tráfego mínimo em concessões rodoviárias de prazo fixo. Fishbein e Babbar (1996) expõem que, ao oferecer garantias, o poder concedente consegue obter financiamento privado para a infra-estrutura, que, de outra forma, teria que ser totalmente financiada com recursos públicos.

Entretanto, o oferecimento de garantias não ocorre sem um preço. Ao estarem protegidos do risco relacionado à demanda, os concessionários podem alterar seu comportamento, não se preocupando com o volume de tráfego que utiliza a sua concessão. Este efeito, é descrito na literatura econômica como perigo moral (moral hazard). Adiciona-se a isso o fato de que, freqüentemente, em conjunto com as garantias de tráfego ou receita mínimos, é utilizado um mecanismo de repartição de receita excessiva (situação de demanda acima do previsto). Com isso, o concessionário pode ser desincentivado a obter aumentos de tráfego a partir de determinado patamar, uma vez que os ganhos serão repassados ao poder concedente.

Ainda, é possível que períodos onde a demanda fique abaixo do previsto coincidam com períodos de contração da economia do país, resultando em menor arrecadação de impostos. Assim, ao oferecer garantias, o caixa do governo seria pressionado por dois lados: menor arrecadação; e maior desembolso.

Guash, Laffont e Straub (2002) encontraram evidências que o uso de garantias pode, inclusive, ter levado a um aumento na probabilidade de renegociação dos contratos. Isto ocorre pela redução dos incentivos aos concessionários agirem eficientemente e/ou encorajando propostas estrategicamente irreais. Além disso, as garantias tornam possível a realização de projetos não justificáveis socialmente ("elefantes brancos"), uma vez que estes não passam pelo teste de mercado, como destacado por Engel, Fischer e Galetovic (1997c).

Além do oferecimento de garantias, outras alternativas foram propostas, buscando reduzir o risco de tráfego pela adoção de mecanismos de endogenização do prazo de concessão. Estes modelos utilizam prazo de concessão variável, que expira quando algum controle atinge níveis estabelecidos no processo de concessão (o valor presente das receitas 
de pedágio ou o valor presente descontado dos custos operacionais). Gómez-Lobo e Hinojosa (2000) apresentam como primeiras experiências com concessões de prazo variável aquelas das pontes Severn Trent e Dartford, no Reino Unido, na década de 1980.

Os mecanismos de prazo variável trazem algumas vantagens importantes para as concessões rodoviárias. Estes benefícios estão relacionados não somente com a redução do risco de tráfego, mas também com a forma de estruturação dos processos licitatórios e dos contratos de concessão. Em geral, os benefícios apresentados foram levantados em discussões sobre o mecanismo de concessão com prazo variável proposto por Engel, Fischer e Galetovic. Contudo, em sua grande maioria, os benefícios podem ser aplicados também para o modelo desenvolvidos por Gustavo Nombela e Ginés de Rus. Entre os benefícios, destacam-se:

- redução do risco de tráfego alocada aos concessionários;

- seleção de licitantes mais eficientes;

- redução de desperdícios econômicos com múltiplos estudos de tráfego com a mesma finalidade;

- menor probabilidade de renegociação;

- flexibilidade dos contratos;

- facilidade para a definição de tarifas diferenciadas (por horário, ou dia da semana, por exemplo) e sua modificação no decorrer da concessão;

- simplicidade do processo de licitação;

- menor necessidade de informação para a regulação;

- redução do risco dos investidores de capital.

Como apontado por diversos autores, como Klein (1997), embora tragam alguns pontos vantajosos em relação às concessões de prazo fixo, os mecanismos de prazo variável não estão imunes a problemas, entre eles:

- transferência do risco de tráfego para os usuários futuros;

- dificuldade relativa aos contratos de dívida;

- dificuldade para a definição da adequada taxa de desconto a ser utilizada nos projetos;

- limitação do retorno obtido pelo concessionário;

- redução no esforço de comercialização (busca de mais usuários);

- redução de qualidade da via;

- organização da concessionária.

Embora possa ser visto como a grande vantagem oferecida aos investidores, a redução no risco de tráfego deve ser vista com ressalvas. Investidores procuram determinados graus de risco, desde que estes riscos sejam remunerados por um prêmio compatível. Assim sendo, reduzir os riscos a níveis mínimos pode afastar potenciais investidores que busquem colocar em seus portfolios de investimentos projetos com riscos mais altos e maior retorno esperado.

\subsection{Mecanismo de Engel, Fischer e Galetovic}

Embora concessões de prazo variável tenham sido realizadas no Reino Unido já no final da década de 1980, o primeiro modelo de concessão com prazo variável proposto academicamente e amplamente discutido foi desenvolvido por Eduardo Engel, Ronald Fischer e Alexander Galetovic, a partir de meados da década de 1990. Este mecanismo ficou conhecido pelo acrônimo LPVR (da denominação em inglês - Least Present Value of Revenues, ou, menor valor presente das receitas). Em sua concepção original, o mecanismo de licitação $L P V R$ possui quatro pontos básicos (Engel, Fischer e Galetovic, 1996):

- o poder concedente fixa o valor máximo de pedágio que pode ser cobrado pelo concessionário;

- é vencedor da concessão o licitante que solicitar o menor valor presente das receitas provenientes da cobrança de pedágio;

- a concessão termina quando o valor presente das receitas de pedágio iguala o valor solicitado pelo licitante vencedor;

- a taxa de desconto utilizada deve ser uma boa estimação da taxa de juros enfrentada pelos concessionários.

Engel, Fischer e Galetovic (1997c) apresentam algumas pequenas variações no modelo básico, de forma a utilizá-lo para concessões de infra-estruturas viárias urbanas mas úteis para quaisquer outras concessões. As alterações são realizadas nos valores de tarifa e na fixação de um prazo limite para a concessão. Os autores incluem ainda que o modelo deve estabelecer os padrões mínimos de qualidade, de forma que uma agência independente possa exercer coerção e/ou aplicar punições quando os níveis de qualidade estabelecidos não forem atingidos.

Embora exponham diversas desvantagens do uso de garantias em concessões com prazo de fixo, Engel, Fischer e Galetovic tecem comentários a respeito do uso de garantias em concessões com prazo variável. Segundo os autores, o uso de garantias seria justificado nos primeiros momentos de um programa de concessões, quando os primeiros concessionários geram conhecimento que será benéfico para os concessionários subseqüentes. Entretanto, assim que as informações a respeito das concessões forem geradas, as garantias devem ser removidas. (Engel, Fischer e Galetovic, 1997c, 1997d) 
Mesmo tendo impacto considerável sobre o risco de tráfego, alguns outros riscos não são reduzidos com a utilização de licitações por menor valor presente das receitas. O concessionário mantém os riscos relativos à construção, manutenção e operação da concessão. Os custos de operação e manutenção da rodovia aumentam com a extensão do prazo de concessão, e reduzem no caso de contração. Este fato gera um contra-incentivo à construção de "elefantes brancos".

De forma a incrementar o contra-incentivo à construção de "elefantes brancos", Engel, Fischer e Galetovic (1996, 1997c) sugerem a aplicação de prazo de concessão máximo, a partir do qual a concessão seja terminada, independentemente de o valor presente das receitas ter sido atingido. Além deste ponto, Izquierdo e Vassallo (2002) expõem que o concessionário obterá um lucro maior quanto maior for o tráfego na rodovia, devido à apropriação da redução dos custos de manutenção e operação da via que teria se esta se estendesse por um período maior. Entretanto, os autores lembram que serão majorados os custos de manutenção (em especial o pavimento) e operação dos anos em que o tráfego ficar acima do previsto.

\subsection{Mecanismo de Nombela e De Rus}

O impacto que os custos de manutenção e operação da rodovia causam em concessões com prazo variável foi o ponto de partida para Gustavo Nombela e Ginés de Rus desenvolverem um modelo que contornasse os problemas do mecanismo de Engel, Fischer e Galetovic. Para Nombela e de Rus (2001), o mecanismo que desenvolveram, conhecido pelo acrônimo LPVNR (do inglês - Least Present Value of Net Revenues, ou, menor valor presente das receitas líquidas) apresenta resultados melhores do que os obtidos em licitações do tipo LPNR.

Nombela e de Rus (2001) argumentam que os custos de operação e manutenção podem não ser desprezíveis como considerado no modelo LPVR. Nestes casos, o concessionário não seria indiferente às variações no prazo de concessão, uma vez que a extensão do prazo implica em maiores custos, reduzindo a lucratividade do projeto, podendo levar, em casos extremos, à necessidade de realizar uma renegociação do contrato.

Nombela e de Rus (2004) argumentam que dados empíricos indicam que os custos anuais de operação e manutenção são pequenos se comparados aos custos de construção da infra-estrutura, mas não podem ser descartados quando avaliados para toda a vida da concessão. Com base em informações do French Highway Directorate, os autores expõem que, para concessões com prazo de 30-40 anos, o valor total de manutenção e operação da concessão é responsável por $25-30 \%$ de todo o custo do projeto.

A solução encontrada para solucionar o problema foi desenvolver um modelo de licitação onde informações relativas aos custos de operação e manutenção fossem requeridas. Segundo Nombela e de Rus (2004), este modelo melhora os resultados obtidos com licitações onde as propostas são apresentadas com somente uma dimensão de informação. Entretanto, os autores argumentam que essa modificação não faz com que o processo deixe de ser simples.

De forma a evitar que os licitantes tenham que utilizar previsões de tráfego para dimensionar suas propostas, o modelo proposto é baseado em propostas com duas dimensões de informação. Aos candidatos é solicitada a apresentação de envelopes selados contendo duas informações:

- receita total a ser obtida com a concessão, sem incluir as estimativas de custos de manutenção e operação da concessão; e

- custos médios anuais de manutenção e operação da infra-estrutura viária.

Nombela e de Rus (2004) explicam que o objetivo do primeiro valor é determinar a duração do contrato, que é variável e depende dos níveis de tráfego, assim como nas concessões do tipo LPVR. Ao solicitar que os licitantes apresentem o segundo valor, tenta-se extrair informações sobre os custos de manutenção e operação da concessionária, ao garantir ao concessionário que este será compensado anualmente pelos custos declarados. Com os dados relativos ao tráfego anual, o poder concedente pode calcular a receita líquida obtida pelo concessionário durante o período. A concessão dura até que a seguinte condição é atingida:

$$
\sum_{i=1}^{T} \frac{\left(R_{i}-E\right)}{(1+\rho)^{i}}=B
$$

onde:

$R_{i}$ - Receita auferida no período de tempo $i$;

$E$ - Custos médios anuais de manutenção e operação da infra-estrutura viária apresentados durante o processo de licitação;

$B$ - Receita total a ser obtida com a concessão, sem incluir as estimativas de custos de manutenção e operação da concessão, apresentada durante o processo de licitação;

$\rho$ - Taxa de desconto utilizada; 
$i$ - Período de tempo da concessão (em um contexto de tempo discreto, poderia ser mês ou ano, por exemplo).

O critério utilizado para selecionar o vencedor do processo licitatório é escolher o licitante com a menor expectativa de custos totais. Dado que será uma concessão com prazo variável, não é razoável estabelecer ex-ante a vida do contrato. Conseqüentemente, não é possível selecionar com absoluta certeza qual a melhor oferta em termos de custos totais. Para solucionar este problema, os criadores do mecanismo LPVNR detalham algumas alternativas, como a utilização de uma faixa de possíveis durações para o contrato.

Mesmo que Nombela e de Rus (2004) especifiquem que não ocorram problemas neste sentido, Izquierdo e Vassallo (2002) expõem que o fato de que diversas variáveis econômicas inter-relacionadas possam ser combinadas no processo de licitação pode levar os licitantes a combinar as variáveis de forma que cheguem a um valor diferente do que poderia ser considerado a combinação mais eficiente do ponto de vista do poder concedente.

Izquierdo e Vassallo (2002), expõem que, ao licitar a concessão com o mecanismo $L P V N R$, os licitantes reduzirão os custos constantes de suas propostas ao máximo possível. Além disso, por uma questão de assimetria de informações, seria complicado para o poder concedente avaliar detalhadamente se os gastos previstos inicialmente serão empregados na manutenção da concessão e, caso sejam, se serão empregados eficientemente. Este fato faz com que a regulação e fiscalização da qualidade sejam necessárias como em qualquer outro método de licitação.

\section{AVALIAÇÃO DOS MECANISMOS}

O trabalho avaliou o comportamento dos resultados da taxa interna de retorno de uma concessão fictícia, caso esta tivesse sido licitada com os mecanismos de concessão com prazo variável. Os mecanismos testados são $L P V R$, desenvolvido por Engel, Fischer e Galetovic (1996, 1997b), e LPVNR, desenvolvido por de Nombela e de Rus (2004).

A concessão utilizada como base para as avaliações foi estruturada de forma semelhante àquelas realizadas no Brasil, com investimentos em ampliação e melhoramentos e posterior operação e manutenção por toda a duração da concessão. Para realização das análises, foi desenvolvido um modelo financeiro específico, em planilha de cálculo Excel, contendo uma estrutura de fluxo de caixa para cada uma das estratégias testadas.

O comportamento dos resultados que a concessão poderia ter quando mecanismos de prazo variável fos- sem utilizados foi estimado com auxílio de simulação Monte Carlo, possibilitando descrever os resultados probabilisticamente. Com base nos resultados das simulações, buscou-se verificar como os mecanismos de concessão de prazo se comportam em condições semelhantes àquelas apresentadas pelo ambiente brasileiro. Assim, verificou-se nos resultados apresentados:

- alteração nos resultados médios e desvio padrão dos resultados da taxa interna de retorno dos projetos quando a taxa de desconto utilizada nos projetos é aumentada;

- alteração nos resultados médios e desvio padrão dos resultados da taxa interna de retorno dos projetos quando a duração esperada para a concessão é aumentada;

- alteração nos resultados médios e desvio padrão dos resultados da taxa interna de retorno dos projetos quando é variada a extensão máxima que pode ser atingida pelo prazo de concessão.

\subsection{Modelo financeiro}

O modelo financeiro utilizado para as simulações permite avaliar o impacto que variações em diversos dados de entrada proporcionam no fluxo de caixa de um projeto de concessão, por toda a duração da concessão. As variáveis do modelo incluem: dados econômicos (alíquotas de impostos, taxas etc.); dados de custos construtivos (custos de implantação dos projetos, melhorias etc.); recursos financeiros (taxas de juros, prazos de pagamento etc.); dados operacionais (custos operacionais, tráfego etc.).

Diferentemente de modelos financeiros desenvolvidos para análises financeiras de concessões de infra-estruturas rodoviárias, como os de World Bank (2003) e Brealey e Myers (2003), o modelo desenvolvido para as análises foi estruturado de forma que a duração das concessões fosse variável, se adequando à necessidade de análise dos mecanismos $L P V R$ e $L P V N R$.

O modelo possui variáveis que são testadas de forma determinística, definidas ex-ante, e de forma estocástica, para aquelas que sofrem variações ao longo do prazo de concessão. Para que fossem avaliados dentro das mesmas condições, os mecanismos foram testados simultaneamente, com as variáveis estocásticas e determinísticas possuindo exatamente os mesmos valores para cada um dos casos.

\subsection{Variáveis e custos da concessão}

A demanda de cada ano é uma variável estocástica, definida por meio de simulação Monte Carlo, podendo assumir valores conforme a distribuição de 
probabilidades a ela associada. Esta é descrita em termos de volumes de tráfego anuais. A demanda de um determinado ano é definida em função do volume de tráfego do ano anterior e do crescimento de tráfego. Nesta abordagem, denominada passeio aleatório (random walk), a demanda de um ano é igual à demanda do ano anterior, multiplicada por um valor igual a 1 (um) mais uma taxa de crescimento gerada aleatoriamente (Motta et al., 2003). O volume de tráfego do primeiro ano de concessão equivale a 15.000.000 de veículos pagantes no ano.

Tanto o tráfego inicial como as taxas de crescimento que podem ser assumidas nas simulações Monte Carlo obedecem distribuições normais, com valor médio igual ao valor esperado. $\mathrm{O}$ desvio padrão do tráfego inicial é igual 750.000 veículos (5\% do valor esperado). O desvio padrão das taxas de crescimento depende do valor esperado para a taxa em cada ano, sendo que o coeficiente de variação é igual a 1. As taxas de crescimento esperadas são: $6 \%$, para os três primeiros anos da concessão; $3 \%$, para o período compreendido entre o quarto ano e o momento em que o tráfego na via concedida atinge $90 \%$ da capacidade admitida como máxima para a concessão, de 40.000 .000 de veículos pagantes anuais; e 1\%, quando o tráfego na concessão supera 36.000 .000 de veículos pagantes anuais.

De forma a simplificar a estrutura de custos de operação e manutenção, os custos da concessão foram divididos em duas partes: custos fixos, representando a maior parte dos investimentos em manutenção; e custos variáveis, diretamente proporcionais à demanda do ano, representando a maior parte dos custos de operação. As tarifas utilizadas nas concessões e nas simulações foram calculadas somente com base nos custos da concessão e nas variáveis utilizadas e no tráfego esperado.

As variáveis determinísticas testadas serão aquelas referentes às taxas de retorno esperadas para os projetos e as durações esperadas para as concessões. As taxas de retorno dos projetos são de: $8 \%$ ao ano (a.a.); 16\% a.a.; e 24\% a.a.. As durações esperadas (horizonte) utilizadas nas análises são de: 12 anos; 18 anos; 24 anos. Ainda, serão utilizados limites máximos para a duração (extensão dos prazos), equivalentes a: $1 / 3$ da duração esperada; $2 / 3$ da duração esperada; igual à duração esperada. Para cada combinação dos valores das variáveis taxa de retorno dos projetos e duração esperada, foram calculadas tarifas que tornassem os projetos auto-sustentáveis.

Os resultados dos mecanismos simulados foram comparados entre si e com aqueles que seriam obtidos por uma concessão de prazo fixo, desprovida de garantias e de mecanismos de divisão de receitas excessivas. $\mathrm{O}$ indicador utilizado para avaliar os modelos foi a taxa interna de retorno dos fluxos de caixa. Não foram consideradas as influências exercidas pela alavancagem financeira dos projetos nem pela possível redução do custo de capital em concessões de prazo variável.

Durante o processo de simulação Monte Carlo foi utilizado o processo de amostragem denominado Latin Hipercube Sampling (LHS). O uso do processo de amostragem LHS é justificado por apresentar resultados melhores do que aqueles obtidos com processo de amostragem Monte Carlo (Vose, 2002).

Foram realizadas 27 simulações, cada qual com 2000 iterações, referentes aos cenários elaborados com a combinação dos três valores possíveis para as três variáveis determinísticas. O número de iterações foi determinado de tal forma que os resultados médios dos indicadores e seus desvios padrões convergissem para um valor. Assim, os valores obtidos com cada nova iteração não alteram de maneira significativa os resultados médios obtidos com as iterações anteriores.

Descrição detalhada do modelo financeiro desenvolvido, informações relativas ao tráfego previsto, custos da concessão utilizadas nas simulações e considerações sobre questões tributárias, podem ser obtidas em Neves da Silva (2004). A concessão fictícia utilizada neste estudo equivale à descrição da concessão do tipo ROT utilizada no trabalho referido.

\section{RESULTADOS OBTIDOS}

Os resultados das simulações foram separados em dois grupos: o primeiro grupo avalia o valor médio atingido pelos indicadores; o segundo grupo avalia da variabilidade dos resultados, por meio do desvio padrão dos resultados. A Tabela 1, a seguir, apresenta os resultados obtidos.

\subsection{Valores médios}

Concessões com mecanismo de prazo variável apresentam taxas internas de retorno superiores àquelas apresentadas por concessões de prazo fixo quando a duração esperada para a concessão e/ou a taxa de desconto são menores. Entretanto, o aumento do valor atribuído a essas variáveis torna os resultados médios atingidos pela TIR maiores em concessões de prazo fixo.

Os resultados médios atingidos pela TIR caem com o aumento do horizonte de concessão, em concessões com mecanismos de prazo variável. A taxa com que os resultados médios atingidos pela TIR decrescem com relação à duração esperada é reduzi- 
Tabela 1 - Resultados obtidos com simulação Monte Carlo para a TIR.

\begin{tabular}{|c|c|c|c|c|c|c|c|c|c|}
\hline \multirow[b]{3}{*}{ Cenário } & \multirow{2}{*}{\multicolumn{3}{|c|}{ Dados dos Cenários }} & \multicolumn{6}{|c|}{ Taxa Interna de Retorno } \\
\hline & & & & \multicolumn{2}{|c|}{ Prazo Fixo } & \multicolumn{2}{|c|}{ LPVR } & \multicolumn{2}{|c|}{ LPVNR } \\
\hline & $\begin{array}{c}\text { Duração } \\
\text { Esperada } \\
\text { (anos) }\end{array}$ & $\begin{array}{c}\text { Duração } \\
\text { Máxima } \\
\text { (anos) }\end{array}$ & $\begin{array}{c}\text { Taxa de } \\
\text { Desconto }\end{array}$ & $\begin{array}{l}\text { Valor } \\
\text { Médio }\end{array}$ & $\begin{array}{c}\text { Desvio } \\
\text { Padrão }\end{array}$ & $\begin{array}{l}\text { Valor } \\
\text { Médio }\end{array}$ & $\begin{array}{l}\text { Desvio } \\
\text { Padrão }\end{array}$ & $\begin{array}{l}\text { Valor } \\
\text { Médio }\end{array}$ & $\begin{array}{l}\text { Desvio } \\
\text { Padrão }\end{array}$ \\
\hline 1 & 12 & 16 & $8 \%$ & $7,929 \%$ & $1,967 \%$ & $8,033 \%$ & $0,310 \%$ & $8,020 \%$ & $0,214 \%$ \\
\hline 2 & 12 & 16 & $16 \%$ & $15,931 \%$ & $2,367 \%$ & $15,959 \%$ & $0,580 \%$ & $15,923 \%$ & $0,533 \%$ \\
\hline 3 & 12 & 16 & $24 \%$ & $23,936 \%$ & $2,841 \%$ & $23,789 \%$ & $1,082 \%$ & $23,744 \%$ & $1,037 \%$ \\
\hline 4 & 12 & 20 & $8 \%$ & $7,929 \%$ & $1,967 \%$ & $8,048 \%$ & $0,250 \%$ & $8,051 \%$ & $0,068 \%$ \\
\hline 5 & 12 & 20 & $16 \%$ & $15,931 \%$ & $2,367 \%$ & $16,050 \%$ & $0,356 \%$ & $16,037 \%$ & $0,272 \%$ \\
\hline 6 & 12 & 20 & $24 \%$ & $23,936 \%$ & $2,841 \%$ & $23,956 \%$ & $0,832 \%$ & $23,922 \%$ & $0,783 \%$ \\
\hline 7 & 12 & 24 & $8 \%$ & $7,929 \%$ & $1,967 \%$ & $8,048 \%$ & $0,248 \%$ & $8,052 \%$ & $0,053 \%$ \\
\hline 8 & 12 & 24 & $16 \%$ & $15,931 \%$ & $2,367 \%$ & $16,066 \%$ & $0,304 \%$ & $16,059 \%$ & $0,195 \%$ \\
\hline 9 & 12 & 24 & $24 \%$ & $23,936 \%$ & $2,841 \%$ & $24,008 \%$ & $0,737 \%$ & $23,980 \%$ & $0,682 \%$ \\
\hline 10 & 18 & 24 & $8 \%$ & $7,904 \%$ & $1,673 \%$ & $7,964 \%$ & $0,410 \%$ & $7,934 \%$ & $0,335 \%$ \\
\hline 11 & 18 & 24 & $16 \%$ & $15,935 \%$ & $1,963 \%$ & $15,768 \%$ & $0,715 \%$ & $15,711 \%$ & $0,679 \%$ \\
\hline 12 & 18 & 24 & $24 \%$ & $23,944 \%$ & $2,455 \%$ & $23,414 \%$ & $1,194 \%$ & $23,354 \%$ & $1,149 \%$ \\
\hline 13 & 18 & 30 & $8 \%$ & $7,904 \%$ & $1,673 \%$ & \begin{tabular}{|l}
$7,999 \%$ \\
\end{tabular} & $0,300 \%$ & $7,991 \%$ & $0,152 \%$ \\
\hline 14 & 18 & 30 & $16 \%$ & $15,935 \%$ & $1,963 \%$ & \begin{tabular}{|l|}
$15,888 \%$ \\
\end{tabular} & $0,529 \%$ & $15,841 \%$ & $0,495 \%$ \\
\hline 15 & 18 & 30 & $24 \%$ & $23,944 \%$ & $2,455 \%$ & $23,506 \%$ & $1,095 \%$ & $23,446 \%$ & $1,052 \%$ \\
\hline 16 & 18 & 36 & $8 \%$ & $7,904 \%$ & $1,673 \%$ & $8,002 \%$ & $0,287 \%$ & $7,998 \%$ & $0,113 \%$ \\
\hline 17 & 18 & 36 & $16 \%$ & $15,935 \%$ & $1,963 \%$ & $15,929 \%$ & $0,452 \%$ & $15,886 \%$ & $0,417 \%$ \\
\hline 18 & 18 & 36 & $24 \%$ & $23,944 \%$ & $2,455 \%$ & $23,535 \%$ & $1,060 \%$ & $23,476 \%$ & $1,018 \%$ \\
\hline 19 & 24 & 32 & $8 \%$ & $7,911 \%$ & $1,467 \%$ & $7,940 \%$ & $0,460 \%$ & $7,901 \%$ & $0,400 \%$ \\
\hline 20 & 24 & 32 & $16 \%$ & $15,940 \%$ & $1,751 \%$ & $15,638 \%$ & $0,800 \%$ & $15,581 \%$ & $0,761 \%$ \\
\hline 21 & 24 & 32 & $24 \%$ & $23,952 \%$ & $2,296 \%$ & $23,270 \%$ & $1,258 \%$ & $23,210 \%$ & $1,212 \%$ \\
\hline 22 & 24 & 40 & $8 \%$ & $7,911 \%$ & $1,467 \%$ & $7,998 \%$ & $0,326 \%$ & $7,978 \%$ & $0,224 \%$ \\
\hline 23 & 24 & 40 & $16 \%$ & $15,940 \%$ & $1,751 \%$ & $15,721 \%$ & $0,700 \%$ & $15,667 \%$ & $0,664 \%$ \\
\hline 24 & 24 & 40 & $24 \%$ & $23,952 \%$ & $2,296 \%$ & $23,300 \%$ & $1,227 \%$ & $23,241 \%$ & $1,181 \%$ \\
\hline 25 & 24 & 48 & $8 \%$ & $7,911 \%$ & $1,467 \%$ & $8,007 \%$ & $0,297 \%$ & $7,993 \%$ & $0,170 \%$ \\
\hline 26 & 24 & 48 & $16 \%$ & $15,940 \%$ & $1,751 \%$ & $15,747 \%$ & $0,665 \%$ & $15,693 \%$ & $0,629 \%$ \\
\hline 27 & 24 & 48 & $24 \%$ & $23,952 \%$ & $2,296 \%$ & $23,307 \%$ & $1,219 \%$ & $23,247 \%$ & $1,173 \%$ \\
\hline
\end{tabular}

da com o aumento do valor da variável. Por sua vez, concessões de prazo fixo sofrem queda nos resultados médios atingidos pela TIR quando a duração esperada varia de 12 para 18 anos, mas aumentam quando o valor é aumentado de 18 para 24 anos.

O aumento na extensão máxima do prazo de concessão aumenta os resultados médios atingidos pela TIR em concessões de prazo variável. Entretanto, a taxa com que ocorre esse aumento é reduzida com o aumento da extensão máxima, fazendo com que aumentos da extensão acima de $2 / 3$ da duração esperada não ofereçam grandes aumentos nos resultados médios atingidos pela TIR. Assim, pode-se dizer que a influência da utilização de um limite para a duração de concessões de prazo variável, desde que este não seja muito baixo, não possui grande influência sobre os resultados.

Por fim, a taxa de desconto utilizada nos projetos aumenta os resultados médios atingidos pela TIR, independente da utilização de mecanismos de prazo variável. Entretanto, a taxa com que os resultados médios atingidos aumentam é diferente entre as concessões de prazo variável e concessões de prazo fixo. Concessões de prazo fixo apresentam crescimentos maiores, fazendo com que, com taxas de desconto menores $(8 \%)$, os resultados médios atingidos pela TIR sejam menores do que aqueles atingidos em concessões com mecanismos de prazo variável. Entretanto, com taxas de desconto maiores $(24 \%)$ as posições se invertem, com as concessões de prazo fixo passando a apresentar resultados médios para a TIR superiores.

\subsection{Desvios padrões}

Com relação aos desvios padrões apresentados pelos resultados atingidos pela TIR das concessões, é possível perceber que concessões com mecanismos $L P V N R$ apresentam desvios menores do que aqueles apresentados por concessões com mecanismo LPVR. Também os desvios apresentados por ambos mecanismos de prazo variável ficam abaixo daqueles apresentados por concessões com prazo fixo.

É possível constatar que os desvios padrões apresentados pelos resultados atingidos pela TIR cres- 
cem pouco com o aumento da duração esperada em concessões de prazo variável. Em concessões de prazo fixo, os desvios são reduzidos com o aumento da duração esperada. As taxas de variação dos desvios permanecem praticamente estáveis, independente do mecanismo de prazo variável ou se a concessão possui prazo de concessão fixo.

Constata-se também que, em geral, os desvios apresentados pelos resultados atingidos pela TIR caem quanto maior for a extensão máxima que o prazo da concessão pode atingir, especialmente aqueles apresentados por concessões com mecanismo LPVNR. A partir de $2 / 3$, os desvios apresentados pelos resultados atingidos pela TIR se aproximam de zero, em concessões com esse mecanismo.

Por fim, pode-se constatar que, em geral, os desvios apresentados pelos resultados atingidos pela TIR aumentam quando as taxas de desconto utilizadas nos projetos são aumentadas, mesmo se forem considerados os coeficientes de variação. As taxas de variação dos desvios com relação às taxas de desconto aumentam à medida que taxas de desconto maiores são utilizadas.

\section{CONSIDERAÇÕES FINAIS}

Embora os resultados obtidos não possam ser generalizados, duas importantes constatações devem ser destacadas da avaliação dos mecanismos de prazo variável quando comparados à concessões de prazo fixo: Os resultados médios tendem a ser menores em concessões de prazo variável; e os desvios padrões são reduzidos com o uso destes mecanismos.

O menor valor apresentado, mesmo que sejam diferenças pequenas, decorre da possibilidade de restrição dos ganhos do concessionário em situações de alta demanda, mais a possibilidade de não compensar as perdas totalmente em situações de baixa demanda. Isto pode ser preocupante para os investidores.

Por outro lado, existe a redução da variabilidade dos resultados e, conseqüentemente, dos riscos dos projetos. Entretanto, o risco de mercado como a demanda pode ser enquadrada é um dos riscos tipicamente assumido pela iniciativa privada desde que sejam remunerados. Além disso, deve-se notar que os desvios padrões apresentados pelos resultados em concessões de prazo variável são muito pequenos. Embora o retorno possa ficar abaixo do esperado, mesmo quando as taxas de retorno são pequenas $(8 \%)$, dificilmente uma concessão teria prejuízo decorrente de problemas relacionados à demanda.

Concessões no Brasil se caracterizam por serem realizadas com altas taxas de desconto e necessitarem de grandes prazos para possibilitar a amor- tização dos investimentos necessários. As taxas de desconto dos projetos não decorrem do alto risco de tráfego, mas de uma composição de fatores. Neste sentido, destaca-se o risco político e regulatório apresentado pelo país e pelo mercado de concessões, onde o marco regulatório é muito deficiente. Como visto nos resultados das avaliações, justamente em condições semelhantes às brasileiras, é que os mecanismos de prazo variável apresentam resultados menos favoráveis se comparados àqueles das concessões de prazo fixo.

Assim, deve-se ser questionada a adoção de mecanismos de prazo variável no Brasil pela redução do risco de tráfego. Os outros pontos benéficos dos mecanismos desenvolvidos podem ser mais relevantes para a nossa realidade do que a redução do risco de tráfego. Mais importante para a realidade brasileira seria o desenvolvimento de mecanismos mais robustos ante os riscos políticos e regulatórios, que oferecessem incentivos melhores para o aumento da qualidade das rodovias concedidas e pudessem repassar para as tarifas os ganhos de produtividade ao longo dos anos.

\section{REFERÊNCIAS}

Brealey, R.A. e S.C. Myers (2003) Principles of Corporate Finance, $7^{\text {a }}$ Ed., McGraw-Hill, CD-ROM anexo.

Demsetz, H. (1968) Why Regulate Utilities. Journal of Laws and Economics, No.11. p. 55-66.

DNER (2000) Relatório Anual de Acompanhamento do Programa de Concessão de Rodovias Federais, Brasília, Brasil.

Engel, E., R. Fischer e A. Galetovic (1996) Licitacion de Carreteras en Chile. Estudios Públicos $n^{\circ}$ 61, Centro de Estudios Públicos, Chile.

Engel, E., R. Fischer e A. Galetovic (1997a) Respuesta a Michael Klein y Jean Tirole. Estudios Públicos n ${ }^{\circ} 67$, Centro de Estudios Públicos, Chile.

Engel, E., R. Fischer e A. Galetovic (1997b) Highway Franchising: Pitfalls and Opportunities. American Economic Review. Vol 87, No 2.

Engel, E., R. Fischer e A. Galetovic (1997c) Como Licitar una Concesión Vial Urbana. Estudios Públicos $n^{\circ}$ 67, Centro de Estudios Públicos, Chile.

Engel, E., R. Fischer e A. Galetovic (1997d) Infrastructure Franchising and Government Garantees. In Irwin, T., M. Klein, G. E. Perry e M. Thobani (eds.) Dealing whith Public Risk in Private Infrastructure. Worldbank Latin American and Caribbean Studies, Washington D.C., EUA.

Fishbein, G. e S. Babbar (1996) Private Financing of Toll Roads. RMC Discution Paper 117.

Gómez-Lobo, A. e S. Hinojosa (2000) Broad Roads in a Thin Country. Policy Research Working Paper 2279, World Bank Institute, World Bank, Washington D.C., EUA.

Guash, J. L., J. J. Laffont e S. Straub (2002) Renegotiation of Concession Contracts in Latin America Infrastructure. Working Paper 3011, The World Bank, Washington D.C., EUA. 
Izquierdo, r. e J. M. Vasallo (2002) Estudio Sobre los Contratos de Concesión de Obras Públicas. Documento Fnal. Comisión de Economía de las Obras Públicas, Colegio de Ingenieros Caminos Canales y Puertos, Madri, Espanha.

Klein, M. (1997) Los Requisitos de uma Política Global de Infraestrutura Vial. Estudios Públicos n ${ }^{\circ}$ 65, Centro de Estudios Públicos, Chile.

Machado, K. (2002) Concessões de Rodovias: Mito e Realidade. Editora Prêmio, São Paulo.

Ministério dos Transportes (2004) Concessões Rodoviárias Federais: Novo Modelo de Concessões. Apresentação das Idéias Iniciais. Ministério dos Transportes, Brasília, janeiro.

Motta, R. R., G. M. Calôba, L. N. Villa-Forte E V. G. Guimarães (2003) Viabilidade Técnico-Econômico de Uma Rodovia Pedagiada com Análise de Riscos - Abordagem Segundo Três Metodologias Distintas. UFRJ, Rio de Janeiro.

Neves da Silva, H (2004) Risco de Tráfego e os Mecanismos de Concessão de Infra-estruturas Rodoviárias com Prazo Variável, Dissertação de Mestrado, LASTRAN/PPGEP UFRGS, Porto Alegre - RS.
Nombela, G. e G. de Rus (2001) Auctions for Infrastructure Concessions with Demand Uncertainty and Unknown Costs. Working Paper, Universidad de Las Palmas de Gran Canaria Departamento de Análisis Econômico Aplicado, Las Palmas, Espanha.

Nombela, G. e G. de Rus (2004) Flexible-Term Contracts for Road Franchising. Transportation Research Part-A, (38), p.163-179.

Pires, J.C.L. e F. Giambiagi (2000) Retorno dos novos investimentos privados em contextos de incerteza: Uma proposta de mudança do mecanismo de concessão de rodovias no Brasil. Textos para Discussão, 81, BNDES, Rio de Janeiro - RJ, Brasil.

Tirole, J. (1997) Comentario a la Propuesta de Engel, Fisher y Galetovic sobre Licitación de Carreteras. Estudios Públicos n ${ }^{\circ}$ 65, Centro de Estudios Públicos, Chile.

Vose, D. (2000) Risk Analysis: A Quantitative Guide. 2a. Ed, John Wiley \& Sons, Ltd, EUA.

World Bank (2003) Toolkit for Public-Private Partnership in Highways. PPIAF, The World Bank, Washington, D.C., CDROM.
Homero Neves da Silva (homeronevesdasilva@tsu.ox.ac.uk) Fernando Dutra Michel (michel@producao.ufrgs.br) Luiz Afonso dos Santos Senna (1senna@producao.ufrgs.br) Antonio Núñez (antonio.nunez@let.ish-lyon.cnrs.fr) Artigo recebido em 8/12/2004 e aprovado em 16/07/2005. 